\title{
Brittle Addison's disease: a new variation on a familiar theme
}

\author{
Geoffrey V Gill, Gareth Williams
}

\begin{abstract}
Summary
Unstable and unpredictable disease control in diabetes or asthma, with frequent hospitalisations, is frequently referred to as 'brittle'. We describe two cases of Addison's disease with recurrent hospitalisations in hypo-adrenal crises. Both patients had significant psychosocial disruption, and failure to take hydrocortisone replacement therapy was admitted in one and biochemically proven in the other. We propose that 'brittle' Addison's disease in these cases was due to poor treatment compliance related to psychosocial factors. These features have particular similarities with the syndrome of brittle diabetes.
\end{abstract}

Keywords: Addison's disease; hypo-adrenalism; diabetes; asthma

The term 'brittle' diabetes has long been used to refer to a small sub-group of insulindependent (Type 1) diabetic patients who suffer life-disrupting glycaemic instability ${ }^{1}$ associated with multiple or prolonged hospital admissions. ${ }^{2}$ The term has also been applied to asthma, describing unpredictable severe declines in respiratory function, also with frequent hospitalisations. ${ }^{3}$ We describe here two patients with Addison's disease who have had repeated admissions with hypo-adrenal crises, and who we believe could be considered to have brittle Addison's disease.

\section{Case histories}

Case 1

A 23-year-old woman had polyglandular autoimmune failure comprising Addison's disease (of 8 years duration), hypoparathyroidism and primary ovarian failure. She was treated with hydrocortisone, alfacalcidol and oestrogen replacement. Between 1992 and 1997 she was admitted nine times with acute Addisonian crises, and on each occasion responded promptly to intravenous saline and hydrocortisone. At clinic visits in between she was consistently hypocalcaemic (eg, Ca 1.43 $\mathrm{mmol} / \mathrm{l}$ with positive Trousseau's and Chvostek's signs). She was also hyperpigmented, frequently had low random plasma cortisol levels, and was often hypotensive. Hydrocortisone dosage was increased to $60 \mathrm{mg} /$ day $(2-3$ times the usual replacement dose), calcium and then magnesium supplements were added, and alfacalcidol was increased to $6 \mu \mathrm{g}$ daily (several times the usual treatment dose). During two of her admissions she was found to have urinary tract infections, but no other precipitants were found. Two of the episodes were lifethreatening. After 1996, however, admissions ceased, and she admitted subsequently that she had taken her tablets only intermittently, depositing most of them in the tank of her pet goldfish (who was apparently unharmed by these ambient electrolyte insults). She came from a broken family, and her father had been violent and had abused alcohol. Apart from one admission coinciding with school exams, however, there was no clear relationship of hospitalisations to life crises, though this was rarely enquired into. Interestingly, though hypo-adrenal problems have ceased, hypocalcaemia persists despite large doses of both alfacalcidol and calcium.

Case 2

A 34-year-old woman was admitted in severe Addisonian crisis. Plasma Na was $126 \mathrm{mmol} / \mathrm{l}$, plasma K $5.9 \mathrm{mmol} / \mathrm{l}$, plasma urea 14.6 $\mathrm{mmol} / \mathrm{l}$, and plasma cortisol $20 \mathrm{nmol} / \mathrm{l}$ with no response to intramuscular tetracosactrin (Synacthen). Adrenal antibodies were positive and hypothyroidism and hypoparathyroidism were also diagnosed. She had a daughter with Type 1 (insulin-dependent) diabetes and had a long history of depression with a parasuicidal drug overdose one year previously. She was discharged well on hydrocortisone, alfacalcidol and thyroxine. Three months later she was again admitted with a further Addisonian crisis of no obvious cause. Over the next 4 years she had 14 further admissions, including six Addisonian crises (usually mild), seven episodes with various vague symptoms, and one with depression. Extensive investigations revealed no other pathology apart from unilateral, and apparently asymptomatic, renal calculi. Random plasma cortisol levels both in hospital and clinic were low $(<50 \mathrm{nmol} / \mathrm{l})$ or undetectable despite prescribed doses of oral hydrocortisone up to $60 \mathrm{mg}$ daily (blood samples were taken 1-4 hours after reported morning doses of 20 or $40 \mathrm{mg}$ of hydrocortisone). Thyroid function tests have also suggested under-replacement despite $300 \mu \mathrm{g}$ thyroxine daily. In addition, serum calcium has been borderline low despite $2 \mu \mathrm{g}$ alfacalcidol daily. She has consistently denied compliance problems, and intermittent hospitalisations continue. 


\section{Discussion}

The term 'brittle' has been used since the 1940s to describe Type 1 (insulin-dependent) diabetic patients with life-disrupting glycaemic instability and often frequent hospitalisations. ${ }^{12}$ The origin of the term is obscure, but it has been ascribed to the American diabetologist Rollin Woodyatt as early as 1940. ${ }^{4}$ In relation to asthma, the term was first used in 1977 by Margaret Turner-Warwick in the $\mathrm{UK}^{5}$ to describe a small sub-group of asthmatic patients with labile and unpredictable airways obstruction. The causes of brittle asthma are uncertain, but psychosocial factors have been implicated in at least some patients. ${ }^{36}$ Brittle diabetes has a more established psychogenic and behavioural base, with manipulation of insulin therapy (to induce ketoacidosis or hypoglycaemia) thought to be the cause in most cases. ${ }^{12}$

Our two patients with recurrent hypoadrenal crises have striking similarities with these brittle syndromes, in particular brittle diabetes. They were young women (as is common in brittle diabetes, ${ }^{2}$ and at least some patients with brittle asthma ${ }^{6}$ ), and both had frequent (see figure) and unpredictable admissions. Poor compliance with hydrocortisone replacement was also either admitted to or biochemically demonstrated. There were psychosocial disruptions at home, and admission to hospital may have been an escape from difficult home circumstances. Omission of insulin in brittle diabetes can provide a similar 'gain' motive by hospitalisation with ketoacidosis. There are also parallels with brittle diabetes regarding therapeutic errors, as doctors often respond to recurrent ketoacidosis by escalating insulin doses, which may in any case never be

1 Tattersall R. Brittle diabetes. Clin Endrocinol Metab 1977;6:403-19

2 Gill GV. The spectrum of brittle diabetes. F R Soc Med 1992;85:259-61.

3 Barnes PJ, Chung KF. Difficult asthma. BMF 1989;299: 695-8.

4 Tattersall RB. Brittle diabetes revisited: the Third Arnold Bloom Memorial Lecture. Diabetic Med 1997;14:99-110.

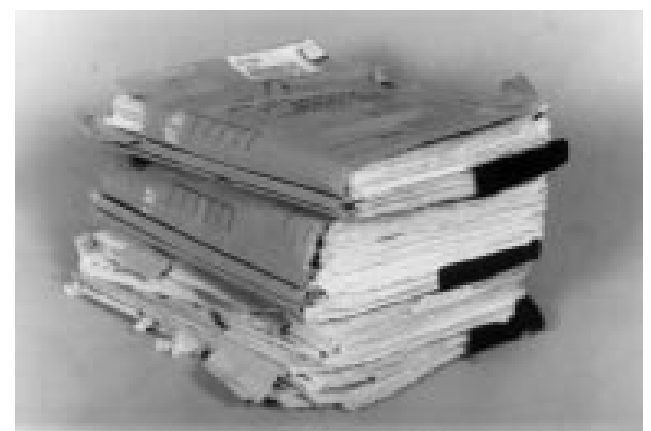

Figure Hospital case notes of a 23-year-old woman with Addison's disease of 8 years duration (Case 1). The record contains details of nine admissions with acute Addisonian crises and 34 out-patient visits

taken! ${ }^{2}$ Both of our patients were eventually prescribed doses of hydrocortisone and alfacalcidol (for hypoparathyroidism) at least 2-3 times the usual replacement doses. This was despite evidence strongly suggesting poor compliance.

Brittle Addison's disease is likely to be a further syndrome of maladaptation to a chronic disease that requires lifestyle change and self-treatment. Like brittle diabetes and brittle asthma, its ideal management is uncertain. There is, however, good evidence that the majority of brittle diabetic patients spontaneously resolve with the passage of time, ${ }^{7}$ and hopefully the same will be true for brittle Addison's disease (eg, Case 1). Unfortunately, the game is a dangerous one to play, and whilst brittle diabetes is active, it is associated with excess mortality and morbidity. ${ }^{7}$

5 Turner-Warwick M. On observing patterns of airflow obstruction in chronic asthma. Br $\mathcal{F}$ Dis Chest 1977;71:7386.

6 Ayres JG, Miles JF, Barnes PJ. Brittle asthma. Thorax 1998; 53:315-21

7 Kent L, Gill GV, Williams G. Mortality and outcome of patients with brittle diabetes and recurrent ketoacidosis. Lancet 1994;344:778-81. 